\title{
APLICAÇÃO DA TÉCNICA DE EXTRAÇÃO DE LINEAMENTOS PARA IDENTIFICAÇÃO DE LOCAIS FAVORÁVEIS A PROSPECÇÃO E CAPTURAS DE ÁGUA SUBTERRÂNEA NO NORTE DO ESPÍRITO SANTO (SUDESTE DO BRASIL)
}

\author{
Viviane dos Santos Coutinho ${ }^{(a)}$, Luiza Leonardi Bricalli ${ }^{(b)}$, Gabriel Pedro Alves Lopes ${ }^{(\mathrm{c})}$ \\ (a) Centro de Ciências Humanas e Naturais/ Universidade Federal do Espírito \\ Santo,vivianecoutinho74@gmail.com \\ (b) Centro de Ciências Humanas e Naturais/ Universidade Federal do Espírito Santo, luiza.bricalli@ufes.br \\ ${ }^{\text {(c) }}$ Centro de Ciências Humanas e Naturais/ Universidade Federal do Espírito Santo, gabriel14pedro@gmail.com
}

\author{
EIXO: GEOTECNOLOGIAS E MODELAGEM ESPACIAL EM GEOGRAFIA FÍSICA
}

\section{Resumo}

\begin{abstract}
Este estudo teve como objetivo principal apontar possíveis áreas de prospecção e captação de água subterrânea no norte do Espírito Santo, sudeste do Brasil. A base metodológica utilizada foi a elaboração de um mapa de lineamentos e um mapa de densidade de lineamentos com principais trendsestruturais sobre Modelo Digital de Elevação (MDE), utilizando o software ArcGis ${ }^{\mathrm{TM}}$ 10.1. Além disso, foram elaboradas rosetas de direções para os lineamentos e para os trends estruturais. Os resultados mostram a presença de grande quantidade de lineamentos nos compartimentos do embasamento pré-cambriano e nas rochas sedimentares cenozoicas. As rochas sedimentares da Formação Barreiras, apresentam, além do faturamento, alta porosidade, e, por isso, apresentam-se mais propícias a infiltração de água subterrânea. A utilização de águas subterrâneas provenientes de aquíferos fraturados pode representar uma alternativa de possível solução para os problemas da crise hídrica que o estado enfrenta.
\end{abstract}

Palavras-chave: Lineamentos; Modelo Digital de Elevação; Espírito Santo; Linhas de fraqueza; Água subterrânea.

\section{Introdução}

Da quantidade total de água existente no Planeta Terra, cerca de 97,5\% corresponde as águas salgadas contidas nos mares e oceanos. Excluindo a água congelada dos polos, a água doce representa apenas $0,6 \%$ do total. Destes, $98 \%$ estão contidas nos aquíferos e apenas $2 \%$ nos rios e lagos (COLERIDGE, 2009).

Frente à crescente demanda dos recursos hídricos, a exploração das águas subterrâneas é uma alternativa para abastecimento, em virtude da sua abundância, qualidade e relativo baixo custo de captação.

A água subterrânea se acumula e circula nos espaços intersticiais das rochas, formando quando as gotas de chuva se infiltram, penetrando em rachaduras e fendas do substrato rochoso (COLERIDGE, 2009). Essas fendas constituem, geralmente, linhas de fraqueza pré-cambrianas ou zonas de fratura da crosta terrestre, que são identificadas, num primeiro momento, a partir da análise de lineamentos (BRICALLI,2011). 


\section{OS DESAFIOS DA GEOGRAFIA FÍSICA NA FRONTEIRA DO CONHECIMENTO \\ Instituto de Geociências - Unicamp \\ Campinas - SP \\ 28 de Junho à 02 de Julho de 2017}

Essa pesquisa teve como objetivo apontar possíveis áreas de prospecção e captação de água subterrânea no norte do estado do Espírito Santo, sudeste do Brasil (Figura 1), a partir da identificação de lineamentos.

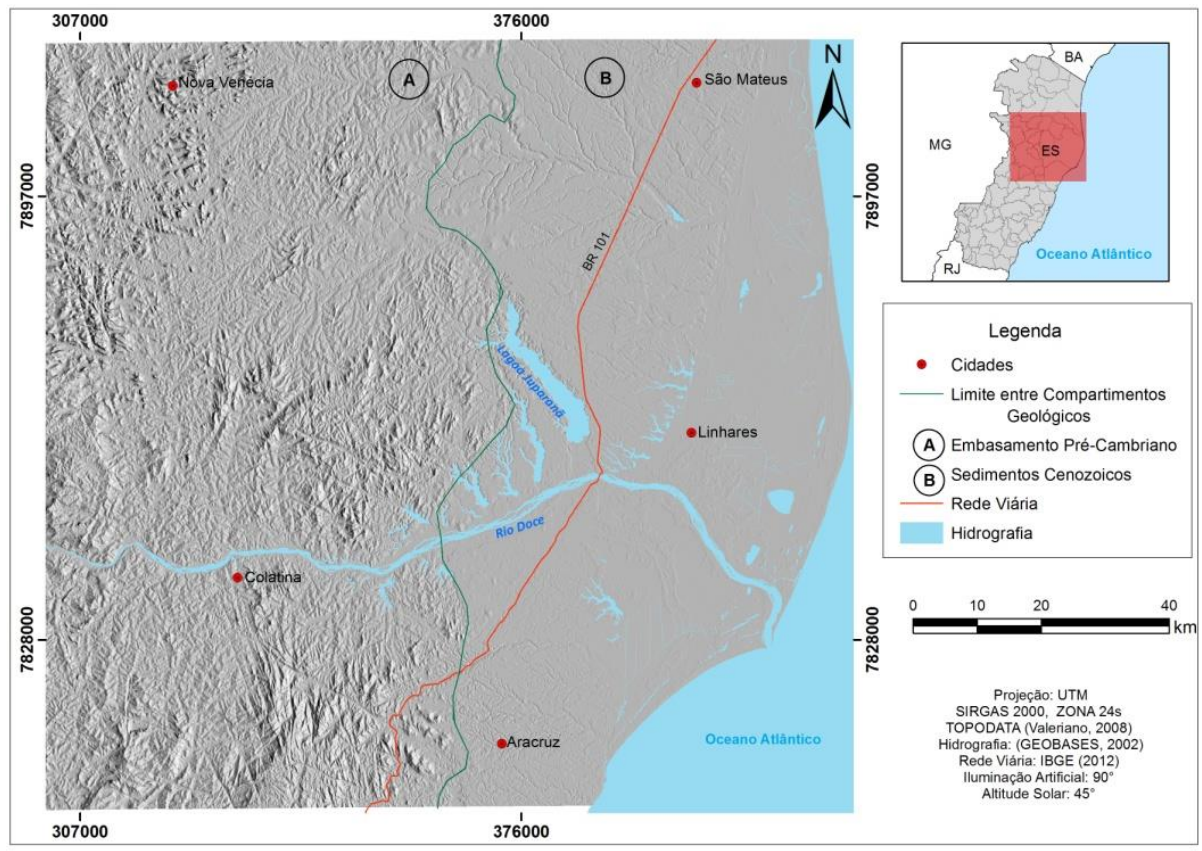

Figura 1 - Mapa de localização da área de estudo: porção norte do estado do Espírito Santo, sudeste do Brasil.

\section{Materiais e Métodos}

\subsection{Análises de lineamentos}

Os lineamentos foram decalcados segundo a metodologia de Bricalli (2011), na escala 1:110.000, sobre um modelo digital de elevação (MDE) do Serviço Geológico Norte-Americano (USGS), referente ao levantamento realizado pela Shuttle Radar TopographyMission (SRTM-NASA), com $\begin{array}{llllll}\text { resolução } & \text { espacial } & \text { de } & 30 \mathrm{~m} & \text { (Topodata) } & -\end{array}$

(http://www.webmapit.com.br/inpe/topodata/). Sobre o MDE foram aplicadas técnicas de iluminações artificiais $\left(0^{\circ}, 45^{\circ}, 90^{\circ}\right.$ e $\left.315^{\circ}\right)$, com o uso do software ArcGIS $10.1^{\mathrm{TM}}$ (ESRI, 2012), disponível para uso da Universidade Federal do Espírito Santo (UFES), afim de ressaltar os lineamentos. Os lineamentos foram identificados segundo a proposta de Liu (1984) que estabelece como lineamentos: linhas de segmentos de escarpas, alinhamento de cristas, vales, trechos de rios e lagos, depressões alongadas e ainda feições lineares separando terrenos através da diferença de textura e feições tonais lineares.

\subsection{Elaboração de rosetas de orientação}

Os valores de direção e comprimento de lineamentos serão representados em diagramas de rosetas através do software Oriana (versão 4.0, license demo) da KovachComputing Services, disponível no site https://www.kovcomp.co.uk/oriana/. 
XVII Simpósio Brasileiro

de Geografia Fisica Aplicada

I Congresso Nacional

de Geografia Física

\section{OS DESAFIOS DA GEOGRAFIA FÍSICA NA FRONTEIRA DO CONHECIMENTO \\ Instituto de Geociências - Unicamp \\ Campinas - SP \\ 28 de Junho à 02 de Julho de 2017}

\subsection{Mapa de densidade de lineamentos}

Foi elaborado o mapa de densidade de lineamentos no software ArcGIS 10.1 ${ }^{\mathrm{TM}}$ (ESRI, 2012), englobando todas as direções, utilizando-se a ferramenta LineDensity, presente no ArcToolbox, com tamanho de célula 30 e unidade da área em $\mathrm{km} / \mathrm{km} 2$.

\section{Resultados e Discussões}

O mapa de lineamentos mostra a presença de uma grande quantidade de lineamentos, tanto nas rochas do embasamento pré-cambriano, quanto nas rochas sedimentares cenozoicas (Figura 2), com uma maior concentração nas rochas do embasamento pré-cambriano, mas com uma significativa presença de lineamentos nas rochas sedimentares cenozoicas (Figura 2).

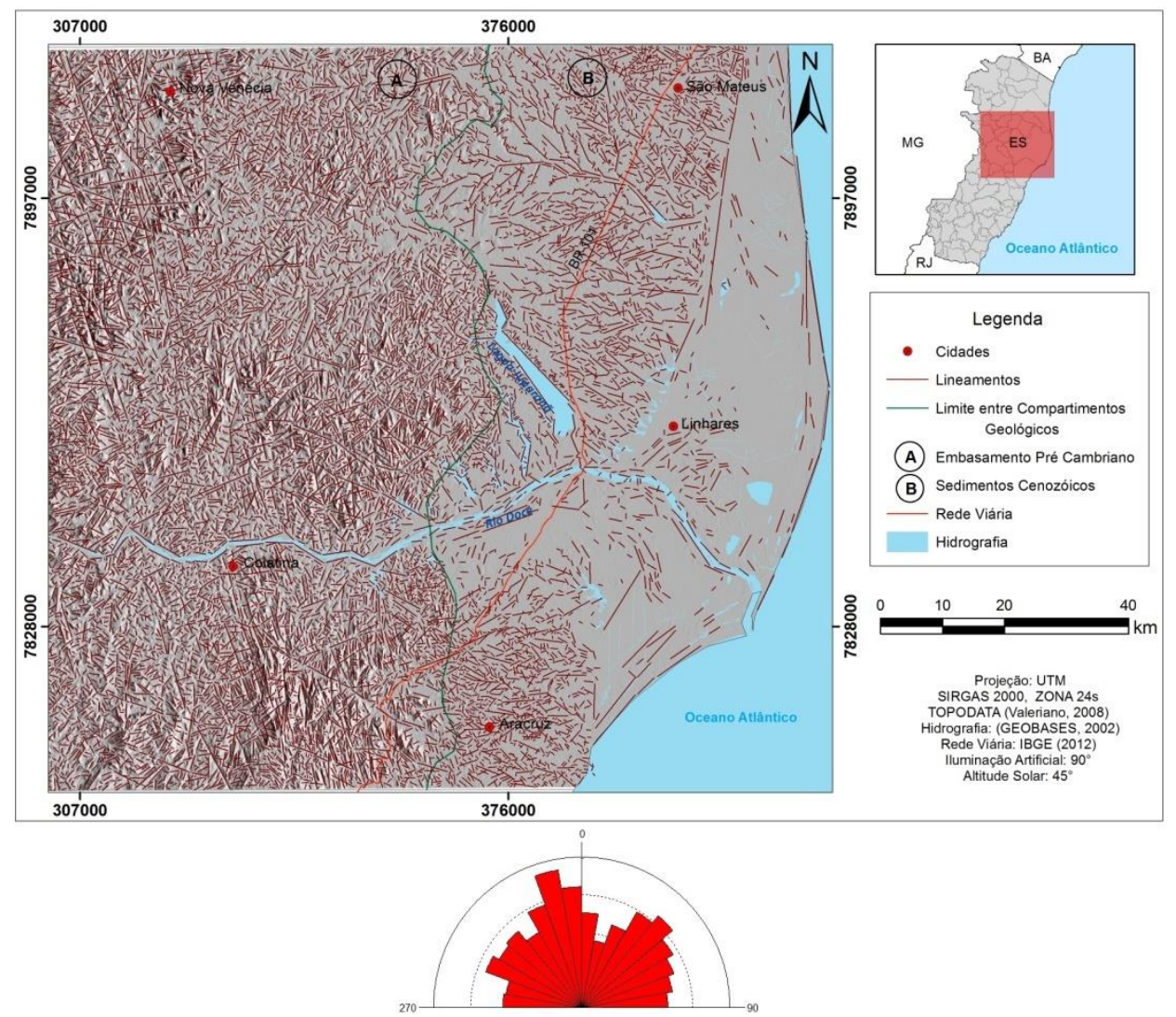

Figura 2 - Mapa de lineamentos sobre Modelo Digital de Elevação (MDE) com iluminação artificial de $90^{\circ}$, mostrando as orientações principais dos lineamentos da porção norte do estado do Espírito Santo, sudeste do Brasil.

Esses lineamentos representam principalmente os cursos d'água e os alinhamentos de vales, pois são justamente áreas de fraquezas da crosta terrestre. Os lineamentos possuem, predominantemente, direções NNW-SSE, NE-SW e NW-SE (Figura 2), respectivamente. Os lineamentos de direção NNWSSE parecem refletir o domínio da Faixa Colatina, relacionada ao regime de transcorrência dextral EW (BRICALLI, 2011). As estruturas de direção NW-SE controlam fortemente a rede de drenagem local e os corpos lacustres da região de Linhares, enquanto os lineamentos de direção NE-SW podem 


\section{OS DESAFIOS DA GEOGRAFIA FÍSICA NA FRONTEIRA DO CONHECIMENTO \\ Instituto de Geociências - Unicamp \\ Campinas - SP \\ 28 de Junho à 02 de Julho de 2017}

ser associados ao padrão de fraturamento gerado no evento de distensão NW-SE Holocênico (BRICALLI, 2011).

O mapa de densidade de lineamentos demonstra a grande densidade de lineamentos nos dois compartimentos geológicos, com maior concentração nas rochas do embasamento pré-cambriano e uma significativa presença de lineamentos nas rochas sedimentares cenozoicas (Figura 3). Além disso, apresenta trends estruturais nas orientações NW-SE e NE-SW, predominantemente, acentuando a influência dos eventos neotectônicos nessa área (BRICALLI, 2011).
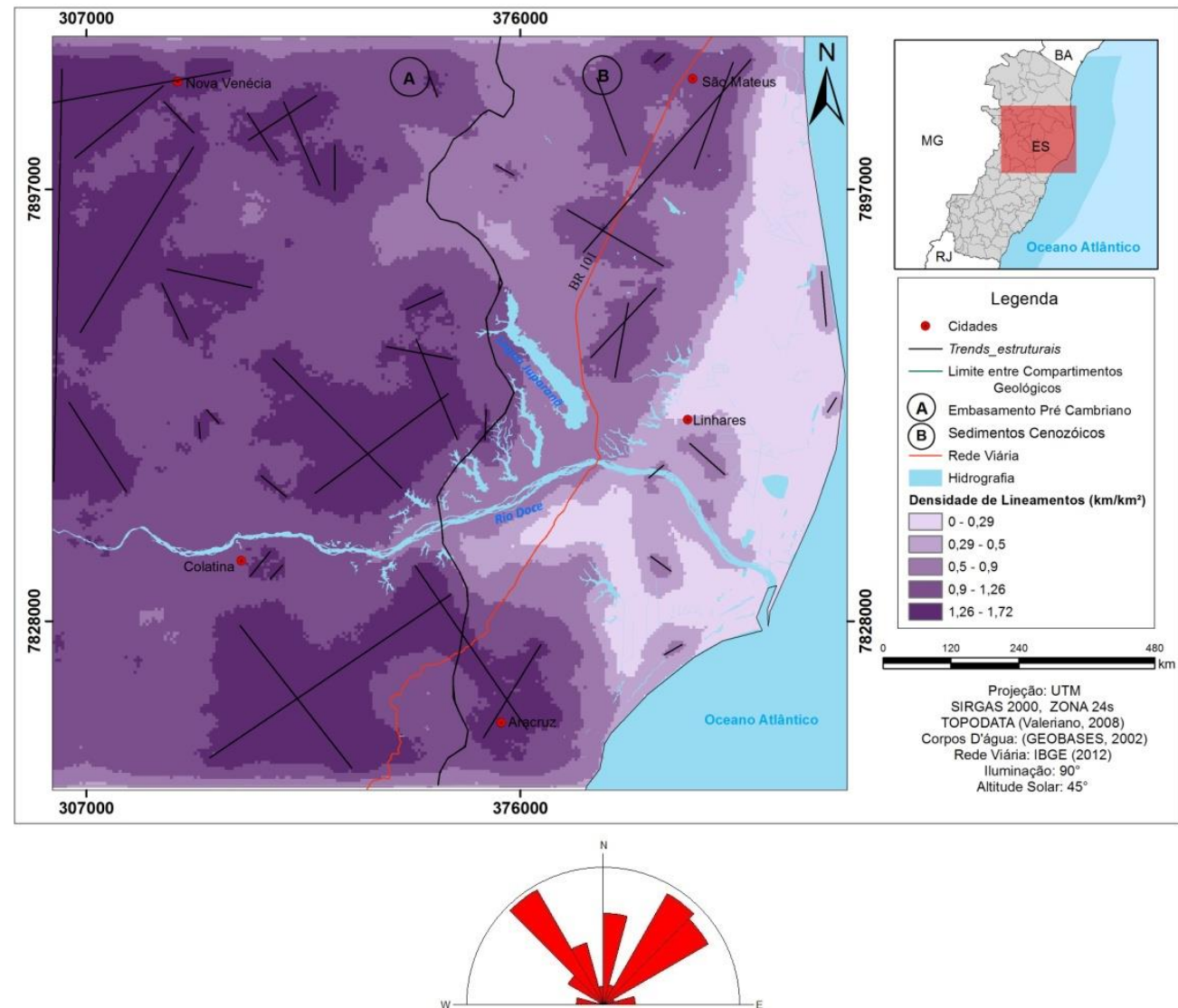

Figura 3 - Mapa de densidade de lineamentos e principais trends estruturais da porção norte do estado do Espírito Santo, sudeste do Brasil.

\section{Considerações Finais}

Através do mapa de lineamentos e densidade de lineamentos (Figuras 2 e 3), nota-se a existência de uma representativa quantidade de lineamentos presentes na área, refletindo a existência significativa de fraturas e descontinuidades litológicas, as quais possibilitam a infiltração de água e, possível captação da mesma.

O compartimento do embasamento pré-cambriano, a oeste da área estudada, representado por rochas do embasamento pré-cambriano, apresenta maior concentração de lineamentos que o compartimento das rocha sedimentares cenozoicas. Esse fato está relacionado às características litoestruturais das 
rochas metamórficas e ígneas do embasamento pré-cambriano. Ressalta-se que as rochas desse compartimento encontram-se bastante e/ou quase totalmente intemperizadas, apresentando assim uma expressiva cobertura quaternária, podendo assim facilitar a captação de água.

O compartimento das rochas sedimentares cenozoicas também apresenta uma expressiva concentração de lineamentos, refletidas pelo faturamento presente, especialmente, nas rochas sedimentares da Formação Barreiras, apresentando também forte controle neotectônico (BRICALLI, 2011). Por serem rochas que apresentam, além do faturamento, características litológicas como alta porosidade, apresentam-se mais propícias a infiltração de água subterrânea.

O Espírito Santo tem apresentado, nos últimos anos, um aumento populacional e uma crescente expansão urbana, ocasionando um aumento na exploração dos recursos hídricos superficiais, para sobrevivência humana, especialmente para agricultura e abastecimento populacional, afetando, a qualidade hídrica e a dinâmica fluvial de bacias hidrográficas. Com isso o estado vem enfrentando a pior crise hídrica dos últimos 40 anos (AGERH, 2016). Nesse contexto a utilização de águas subterrâneas provenientes de aquíferos fraturados pode apresentar como uma alternativa de possível solução para esses problemas.

\section{Referências Bibliográficas}

BRICALLI, L.L. Padrões de Lineamentos e Fraturamento Neotectônico no estado do Espírito Santo (sudeste do Brasil). 2011.221p. Tese (Doutorado em Geologia) - Instituto de Geociências, Universidade Federal do Rio de Janeiro, Rio de Janeiro, 2011.

COLERIDGE, S.T. O Ciclo Hidrológico e a Água Subterrânea. In: Para entender a Terra.2009. 656p.

ESRI. ArcGIS® $10 \quad-\quad$ ArcMap $^{\mathrm{TM}} \quad$ Tutorial. 2012. Disponível em: <http://resources.arcgis.com/en/help/main/10.1/>. Acesso em 20 abril 2015.

GEOBASES - Sistema Integrado de Bases Georreferenciadas do estado do Espírito Santo (Geobases) Plano de informações: hidrografia, rodovias e malha municipal, área urbana, Limite de bairros, Logradouros. Fornecido pelo Laboratório de Cartografia Geográfica e Geotecnologias (LCGGEO) em 2013.

LIU,C.C. 1984.Análise Estrutural de lineamentos em imagens de sensoriamento remoto: aplicação ao estado do Rio de Janeiro. Programa de Pós-graduação em Geocências, Universidade de São Paulo, Tese de Doutorado, $157 \mathrm{p}$.

VALERIANO, M. M. Modelos digitais de elevação de microbacias elaborados com krigagem. São José dos Campos, SP: INPE: Coordenação de Ensino, Documentação e Programas Especiais (INPE-9364-RPQ/736). 54p., 2002.

ESPÍRITO SANTO. Agência Estadual de Recursos Hídricos- AGERH, Disponível em:<https://agerh.es.gov.br//> Acesso em: 05 abr. 2016. 
Agradecimentos: à Universidade Federal do Espírito Santo (UFES) pela bolsa concedida para realização da pesquisa de extensão e ao Grupo de pesquisa Neotectônica no Espírito Santo, pelas valiosas discussões. 